This is not the version of record. The full version of Shaltout, Eman, Al-Dewik, Nader, Samara, Muthanna, Morsi, Hisham and Khattab, Azhar (2020)

Psychological comorbidities in autism spectrum disorders. In: Essa, M. Mohamed and Qoronfleh, M. Walid, (eds.) Personalized food intervention and therapy for autism spectrum disorder management. Cham, Switzerland : Springer. pp. 163191. (Advances in Neurobiology, no. 24) ISSN (print) 2190-5215 ISBN 9783030304010 can be found at: https://doi.org/10.1007/978-3-030-30402-7 6 


\section{Psychological Comorbidities in Autism Spectrum Disorders}

\section{Eman Shaltout ${ }^{1,2}$, Muthanna Samara ${ }^{2 *}$, Hisham Morsi ${ }^{2,6}$, Azhar Khattab ${ }^{5}$, Nader Al- Dewik $^{3,4}$}

Affiliation:

${ }^{1}$ Medical Research Center, Hamad Medical Corporation (HMC), Doha, Qatar

${ }^{2}$ Department of Psychology, Kingston University London, Kingston upon Thames, UK

${ }^{3}$ Clinical and Metabolic Genetics, Pediatrics Department, Hamad General Hospital (HGH), Hamad Medical Corporation (HMC), Doha, Qatar

${ }^{4}$ College of Health and Life Sciences, Hamad Bin Khalifa University (HBKU), Doha, Qatar

${ }^{5}$ Qatar Rehabilitation Institute, Pediatric Rehabilitation, Hamad Medical Corporation (HMC), Doha, Qatar

${ }^{6}$ Quality of Life unit, National Center for Cancer Care and Research, (NCCCR), Hamad Medical Corporation (HMC), Doha, Qatar

*Corresponding author

Professor Muthanna Samara

Email: M.Samara@kingston.ac.uk

Department of Psychology, Kingston University London, Penrhyn Road, Kingston upon Thames, KT1 2EE, UK

Tel: +44 (0) 2084172533

\section{Highlights}

- Substantial overlapping occurs between autism spectrum disorders (ASDs) and psychological disorders.

- Mood disorders, anxiety disorders and ADHD, are among the psychological disorders most frequently related with ASD.

- Symptom presentation is similar whether ASD occurs alone or with other conditions.

- Numerous assessments after initial diagnosis of ASD are commonly required.

- The majority of the ASDs patients had poor QoL. 


\begin{abstract}
Summary
Autism Spectrum Disorder (ASDs) is characterized by impairment in behavior, communication and social interaction. Thus, accurate identification, regular behavioral and other non-medical interventions would improve the diagnosis, management, and treatment of this condition.

In this chapter, we investigate the importance of diagnosing and identifying co-morbid psychiatric disorders that occur with ASD as these conditions can often complicate the treatment, and failure to recognize them can result in deficits that can persist into adolescence and adulthood. In addition, we explore the impact of a comprehensive psychological intervention in ASD patients with comorbid psychiatric disorders with the ultimate goal of improving overall quality of life.
\end{abstract}

Keywords: Autism spectrum disorders, Psychiatric co-morbidities, Cognitive behavior therapy, Psychological interventions 


\section{Introduction}

Central autism features like behavior, social and communication impairments are welldocumented lifetime functional deficits (American Psychiatric Association, 2013).

The role of psychology in ASDs is classically to provide a comprehensive roadmap to evaluate patients' weaknesses and strengths, and provide a guide for treatment in these areas. Subsequent recommendations are based on afflicted patients' cognitive, behavioral, emotional and, academic or vocational needs. The overall aim is to improve functioning by identifying and adjusting maladaptive behaviors associated with the diagnosis; as well as, helping patients and their families succeed at key transition points such as starting school, entering adolescence and moving into adulthood (Weitlauf et al., 2014).

Each individual with ASD is unique and has a range of strengths and challenges. Some ASD individuals are able to succeed in their traditional schools, hold jobs and perform functions of daily living with varying levels of support. Others have substantial intellectual impairments, need to be integrated into special schools and need extensive support and assistance throughout their lives. The reality of this disorder as a wide spectrum of symptom severity throws into light the importance of a dynamic and holistic approach to diagnosis as well treatment.

\section{Diagnostic criteria of ASD}

One of the biggest changes in the DSM 5 (American Psychiatric Association, 2013) was to introduce ASD. Previously, in the DSM IV (American Psychiatric Association, 1994), autistic symptoms were categorized intro four groups: autistic disorder, Asperger's disorder, childhood disintegrative disorder, or the broader diagnosis of pervasive developmental disorder not otherwise specified. The main reason for this shift in diagnostic criteria was to limit the inconsistency in diagnosis across medical centers and practitioners; ultimately creating a comprehensive unified structure for assessing autism that would allow for greater efficacy in developing treatment plans (APA, 2013). Table 1 highlights the DSM 5 diagnostic criteria for ASD (APA, 2013). 
$\underline{\text { Table 1- DSM } 5 \text { diagnostic criteria for ASD }}$

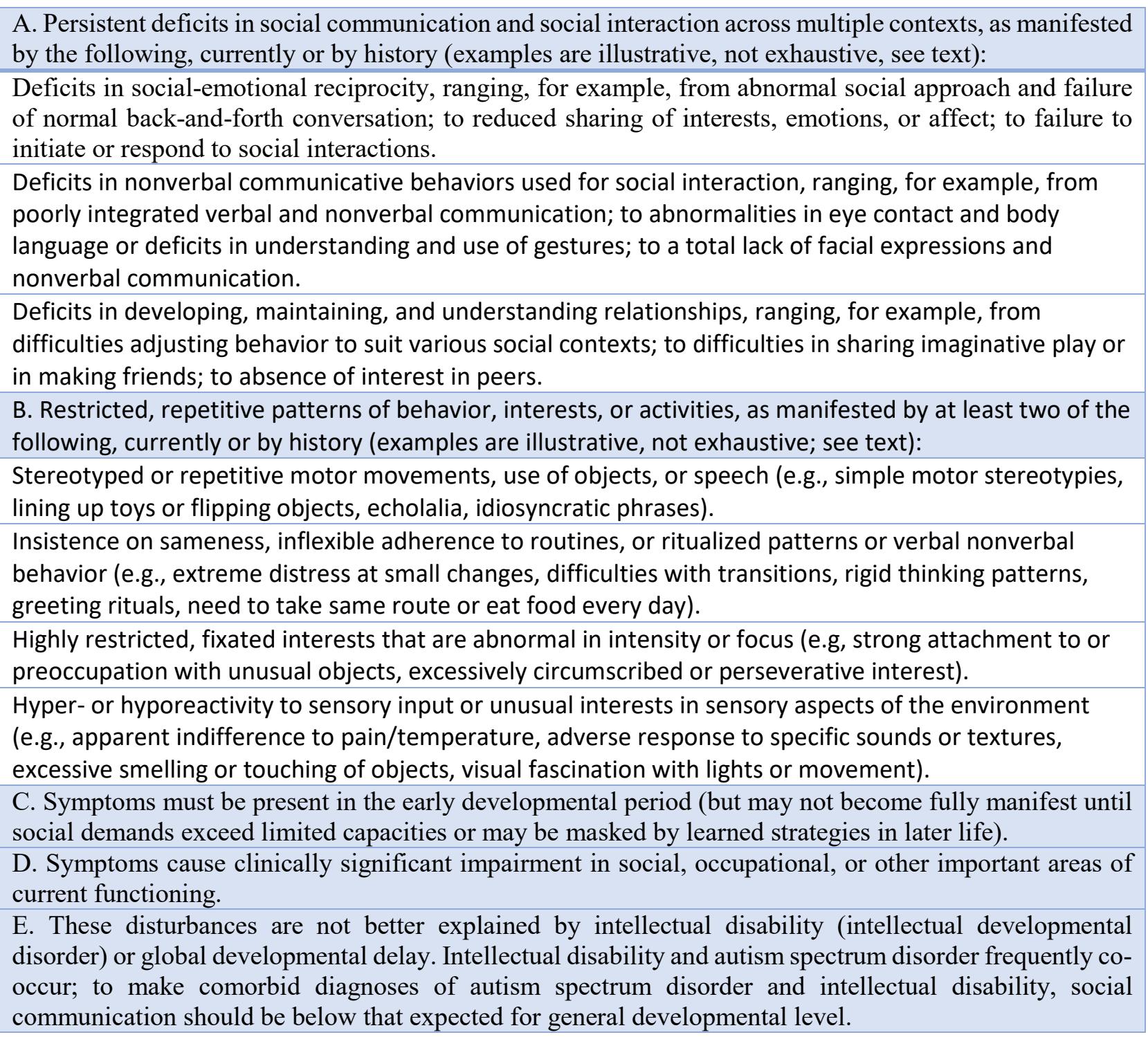

For diagnostic clusters A and B, it is necessary to specify severity of symptoms based on social

communication impairments and restricted, repetitive patterns of behavior into 3 levels

(requiring support, requiring substantial support, requiring very substantial support). Considering

the effect on the treatment plan, practitioners should also specify if:

- With or without accompanying intellectual impairment

- With or without accompanying language impairment

- Associated with a known medical or genetic condition or environmental factor

- Associated with another neurodevelopmental, mental, or behavioral disorder

- With catatonia 


\section{Comorbid psychological conditions in ASDs}

While the DSM 5 goes to some length to standardize the method for assessing impairments or medical and neurodevelopmental disorders that co-occur with autism, it fails to do the same for psychological co-morbidities. In fact, the DSM 5 remains dependent on categorical definitions of psychological disorders, rather than dimensional classifications (Frenz, 2016).

The limitation in the DSM 5 to standardize assessment of co-morbidities generates a major gap in the ability to create an effective treatment plan that adequately meets the individual needs of each patient, and subsequently improve function. A burgeoning area of research has attempted to document the importance of identifying co-morbidities in ASD. In a twin study in Sweden, Lundstrom (2013) found that half of 272 ASD patients had 4 or more co-existing disorders and that only 4\% did not have a comorbid diagnosis. Talisa (2015) found that some neuropsychiatric and behavioral conditions are related to anxiety, and not autism; indicating that failure to diagnose this would result in an inability to adequately improve function. Practitioners should become attuned to spotting signs for existing comorbidities like: a severe and incapacitating problem behavior, worsening of symptoms or abrupt changes from baseline, and not responding to treatment as expected. Should these issues arise, a thorough assessment of psychological comorbidities should be undertaken using standardized assessment tools like:

- Young Mania Rating Scale (YMRS)

- Inventory of Depressive Symptomatology (IDS)

- Structured Clinical Interview for DSM IV for personality disorders (SCID-II)

- Structured Clinical Interview for DSM IV Childhood Diagnoses (Kid SCID)

Psychological conditions that commonly occur with ASDs are diverse, comprising of mood disorders (depression and bipolar), anxiety disorders, obsessive-compulsive disorder, attentiondeficit/ hyperactivity disorder (ADHD). These conditions were found to be biologically based, and situation-induced. In the following sections, each of these disorders will be discussed but will be preceded by their DSM-5 diagnostic criteria. 


\section{Depression and bipolar disorder}

In the DSM IV depressive disorders and bipolar disorders were grouped under the category of 'mood disorders', however in the DSM 5 these were reclassified into separate categories. Despite this, the diagnostic criteria for major depressive disorder (MDD) and bipolar I and II have remained more or less the same and changes were mostly conceptual in nature. Tables $2-4$ outline the DSM 5 diagnostic criteria for MDD, bipolar disorder I and II, respectively.

$\underline{\text { Table } 2 \text { - DSM } 5 \text { criteria for Major Depressive Disorder }}$

\section{Major Depressive Disorder}

The individual must experience five or more symptoms during the same 2-week period and at least one of the symptoms should be either (1) depressed mood or (2) loss of interest or pleasure.

1. Depressed mood most of the day, nearly every day.

2. Markedly diminished interest or pleasure in all, or almost all, activities most of the day, nearly every day.

3. Significant weight loss when not dieting or weight gain, or decrease or increase in appetite nearly every day.

4. A slowing down of thought and a reduction of physical movement (observable by others, not merely subjective feelings of restlessness or being slowed down).

5. Fatigue or loss of energy nearly every day.

6. Feelings of worthlessness or excessive or inappropriate guilt nearly every day.

7. Diminished ability to think or concentrate, or indecisiveness, nearly every day.

8. Recurrent thoughts of death, recurrent suicidal ideation without a specific plan, or a suicide attempt or a specific plan for committing suicide

Table 3 - DSM 5 criteria for Bipolar Disorder I

\section{Bipolar Disorder I}

A. Characterized by the occurrence of 1 or more manic or mixed episodes (the manic episode may have been preceded by and may be followed by hypomanic or major depressive episodes, but these are not required for diagnosis)

B. Distinct period of abnormally and persistently elevated, expansive, or irritable mood, and increased goal-directed activity or energy lasting $\geq 1$ week (any duration if hospitalized), present most of the day, nearly every day

C. During the mood disturbance and increased energy or activity, at least 3 (or 4 if irritable mood only) of the following:

- Inflated self-esteem or grandiosity

- Decreased need for sleep

- Pressured speech

- Racing thoughts or flight of ideas

- Distractibility

- Increased activity

- Excess pleasurable or risky activity.

D. Marked impairment not due to a substance or medical condition. In addition, these symptoms:

A. Do not meet criteria for a mixed episode

B. Cause functional impairment, necessitate hospitalization, or there are psychotic features

C. Are not related to substance misuse

D. Are not due to a general medical condition

E. Are not caused by somatic antidepressant therapy. 


\section{Table 4 - DSM 5 criteria for Bipolar Disorder II}

\section{Bipolar Disorder II}

A. Never had a full manic episode; at least 1 hypomanic episode and at least 1 major depressive episode

B. Distinct period of abnormally and persistently elevated, expansive, or irritable mood, and increased goal-directed activity or energy lasting $\geq 4$ but $<7$ days, and clearly different from usual non-depressed mood, present most of the day, nearly every day

C. During the hypomanic episode, at least 3 (or 4 if irritable mood only) of the following:

- Inflated self-esteem or grandiosity

- Decreased need for sleep

- Pressured speech

- Racing thoughts or flight of ideas

- Distractibility

- Increased activity

- Excess pleasurable or risky activity.

D. Episode is unequivocal change in functioning, uncharacteristic of person, and observable by others

E. Not severe enough to cause marked impairment, not due to substance or medical condition, and no psychosis (if present, then this is mania by definition)

F. During the major depressive episode, at least 5 of the following symptoms are present during the same 2-week period, and represent a change from previous functioning. At least one of the symptoms is either depressed mood or loss of interest or pleasure:

- Depressed mood most of the day, nearly every day

- Markedly diminished interest or pleasure, nearly every day

- Significant weight loss when not dieting or weight gain, or decrease or increase in appetite, nearly every day

- Insomnia or hypersomnia, nearly every day

- Psychomotor agitation or retardation, nearly every day

- Fatigue or loss of energy, nearly every day

- Feelings of worthlessness or excessive or inappropriate guilt (which may be delusional), nearly every day

- Diminished ability to think or concentrate, or indecisiveness, nearly every day

- Recurrent thoughts of death (not just fear of dying), recurrent suicidal ideation with or without a specific plan.

G. In addition, these depressive symptoms:

- Cause functional impairment (e.g., social, occupational)

- Are not better explained by substance misuse, medication side effects, or other psychiatric or somatic medical conditions.

Postorino, Vicari and Mazzone (2016) reported the prevalence of co-occurrence of mood disorders (such as bipolar and depression) in ASDs to be between $1.4 \%$ to 70 \%. (Lainhart \& Folstein, 1994; Wozniak et al., 1997; Ghaziuddin \& Greden, 1998; Green et al. 2000; Kim et al., 2000; Barnhill \& Smith, 2001; Stahlberg et al., 2004; Brereton et al., 2006; Hedley \& Young, 2006; Leyfer et al., 2006; De Bruin et al., 2007; Vickerstaff et al., 2007; Munesue et al., 2008; Simonoff et al., 2008; 
2012; Sterling et al., 2008; Williamson et al., 2008; Hofvander et al., 2009; Whitehouse et al., 2009; Mattila et al., 2010; Lugnegãrd et al., 2011; Mazefsky et al., 2011; Rosenberg et al., 2011; Amr et al., 2012; Joshi et al., 2013; Mazzone et al., 2013; Pouw et al., 2013; Strang et al., 2012; Cassidy et al., 2014; Gotham et al., 2014; Henry et al., 2014). The previous studies used different criteria and different assessment tools, both self-report and clinician administered, which can greatly alter the diagnosis, especially when taking into account the capabilities of the child (Chandrasekhar \& Sikich, 2015). The wide variance of this prevalence highlights the importance of a single standardized diagnostic method and assessment for psychiatric disorders.

There is evidence to support that mood disorders are associated with greater adaptability in ASD. Several studies found that symptoms of depression and mania are directly correlated with higher levels of functioning and adaptation, more insight or self-awareness of own impairments, and a higher cognitive level of functioning (Sterling, 2008; Ghaziuddin, 2002). Similarly, Vickerstaff et al. (2007) found that there are significant associations between self-perception of social competence and depressive symptoms. In addition, high-functioning autism (HFA) patients were found to be predominantly afflicted with mood disorders (Ghaziuddin and Greden 1998; Kim et al., 2000; Mazzone et al., 2013; Munesue et al., 2008; Stewart et al., 2006; Vickerstaff et al., 2007; Whitehouse et al., 2009; Joshi et al., 2013). These rates of comorbid mood disorders were found to be even higher in adolescent and adult HFA patients (Cassidy et al. 2014; Hofvander et al., 2009; Lugnegãrd et al., 2011; Stahlberg et al., 2004; Sterling et al., 2008).

Conversely, other reports indicate that with more severe symptoms of autism, patients are more vulnerable to stressors, as well as to the development of depression (Pearson, 2006; Ghaziuddin, 1995). This is compounded further by Mazurek's (2010) findings that poorer quality of friendship is correlated with higher levels of anxiety and depression indicating the importance for protective factors to general stressors. Depression-induced regression was found to be noticeably present mainly in low functioning autism patients who are characterized by loss of language, social withdrawal, loss of eye contact, moodiness, tantrums, fearfulness, obsessiveness, stereotypies, hyperactivity, and occasionally self-injurious behaviors (Ghaziuddin et al., 2002; Myers \& Winters, 2002). 
Age was also found to be a significant predictor of comorbid depression as symptoms were found to increase with age; with emotional age being a more reliable predictor of the development of depression than chronological age (Vickerstaff, 2007). Several studies also showed that the age of onset of co-occurrence of depression is predominantly around pre-adolescence and adolescence. This could be attributed to the transition period of ASD patients becoming more conscious of their own social skills as well as awareness of lower self-perceived social competence (Ghaziuddin et al. 2002; Mazzone et al. 2012; Williamson et al., 2008; Brereton et al., 2006; Ghaziuddin et al., 2002; Vickerstaff et al., 2007).

The diagnosis of depression is substantially based on self-report of feelings and how those feelings impact daily functioning; this is often difficult to obtain in the ASD population due to inherent impairments in social interaction and verbal communication.

From a clinical point of view, the diagnosis of depression in ASD remains a challenge. Despite characteristic symptoms being recognized, such as depressed mood, irritability, anhedonia, sleep or appetite disturbances, cognitive problems like impaired concentration, indecision, feelings of hopelessness, morbid thoughts, and somatic complaints. Other symptoms are often neglected in observation of ASD patients like aggression, mood lability, hyperactivity, decreased self-care, decreased level of functioning, regression, changes in core symptoms, increased compulsions, selfinjurious behavior, catatonia, and overall changes in adaptive functioning (Magnuson, 2011). The failure to identify these symptoms as depression and assuming them as an extension of the ASD diagnosis can lead to loss of the patient's ability to learn new skills that might greatly improve their ability to live with ASD and may lead to missing suitable interventions that could deal with these problems. 


\section{Anxiety Disorders}

Anxiety disorders in the DSM 5 include: separation anxiety disorder, selective mutism, specific phobia, social phobia, panic disorder, agoraphobia, and generalized anxiety disorder (GAD). The common symptoms across each of these diagnoses is best explained by the diagnostic criteria for GAD in table 5.

\section{$\underline{\text { Table } 5 \text { - DSM } 5 \text { diagnostic criteria for Generalized Anxiety Disorder }}$}

\section{Generalized Anxiety Disorder}

A. The presence of excessive anxiety and worry about a variety of topics, events, or activities.

Worry occurs more often than not for at least 6 months and is clearly excessive.

B. The worry is experienced as very challenging to control. The worry in both adults and children may easily shift from one topic to another.

C. The anxiety and worry are accompanied with at least three of the following physical or cognitive symptoms. (In children, only one symptom is necessary for a diagnosis of GAD):

- Edginess or restlessness

- Tiring easily; more fatigued than usual

- Impaired concentration or feeling as though the mind goes blank

- Irritability (which may or may not be observable to others)

- Increased muscle aches or soreness

- Difficulty sleeping (due to trouble falling asleep or staying asleep, restlessness at night, or unsatisfying sleep)

Due to the nature of ASD heavily impairing social and communication skills, school-age children and adolescents are often commonly afflicted with anxiety-related concerns (Ghaziuddin 2002). Simonoff et al (2008) supported this further with findings showing that $41.9 \%$ of 112 ASD children aged from $10-14$ years met the criteria for at least one anxiety disorder.

Reported prevalence of anxiety in ASD varies widely, with estimates ranging from 13.6 to $84.1 \%$ (Bellini 2004; Bradley et al. 2004; Kim et al. 2000 ; Muris et al. 1998 ; Lidstone et al. 2014 ). A recent systematic review obtained from 31 studies (van Steensel et al., 2011) identified that clinically significant levels of anxiety were present in $39.6 \%$ of a pooled sample of 2,121 individuals under the age of 18 with ASD. Although findings are inconsistent, the most frequent anxiety disorders in ASD appear to be specific phobias, generalized anxiety disorder, separation anxiety disorder, and social phobia; with social anxiety being the most prevalent in ASDs (29.2\%) (Muris et al., 1998; Evans et al., 2005; Gadow et al., 2005; Weisbrot et al., 2005; de Bruin et al., 2007; Gillot \& Standen, 2007; Sukhodolsky et al., 2008). 
While Sukhodolsky et al. (2008) similarly found that 43\% of 171 ASD children aged from 5 - 14 years met the criteria for at least one anxiety disorder. They also reported that increased anxiety was associated with higher IQ, as well as with less ASD severity, which could be attributed to more self-awareness of social dysfunction.

ASD children presented with a distinctive set of fears when compared to chronological- and mental- age matched peers, reporting more frequent situation phobias and medical fears, but less often related to fears of being harmed or injured (Evans et al., 2005)

In conclusion, anxiety seems to be more common in ASD than in both the general population and several clinical groups, with probably up to $40 \%$ of ASDs patients presenting with at least one anxiety subtype. 


\section{Obsessive-Compulsive Disorder}

Obsessive-compulsive disorder (OCD) is characterized by recurrent disturbing thoughts or images, and repetitive behaviors. In the DSM IV, OCD was previously categorized as an anxiety disorder however in the DSM 5 it was reclassified as a distinct disorder due to the focus on the behavioral component. Table 6 describes the DSM 5 criteria for diagnosing OCD.

\section{Table 6-DSM 5 diagnostic criteria for Obsessive Compulsive Disorder}

\section{Obsessive Compulsive Disorder (OCD)}

\section{A. Presence of obsessions, compulsions, or both:}

- Obsessions are defined by (1) and (2):

1. Recurrent and persistent thoughts, urges, or impulses that are experienced, at some time during the disturbance, as intrusive and unwanted, and that in most individuals cause marked anxiety or distress.

2.The individual attempts to ignore or suppress such thoughts, urges, or images, or to neutralize them with some other thought or action (i.e., by performing a compulsion).

- Compulsions are defined by (1) and (2):

1. Repetitive behaviors (e.g., hand washing, ordering, checking) or mental acts (e.g., praying, counting, repeating words silently) that the individual feels driven to perform in response to an obsession or according to rules that must be applied rigidly.

2.The behaviors or mental acts are aimed at preventing or reducing anxiety or distress, or preventing some dreaded event or situation; however, these behaviors or mental acts are not connected in a realistic way with what they are designed to neutralize or prevent, or are clearly excessive.

B. The obsessions or compulsions are time-consuming (e.g., take more than 1 hour per day) or cause clinically significant distress or impairment in social, occupational, or other important areas of functioning.

C. The obsessive-compulsive symptoms are not attributable to the physiological effects of a substance (e.g., a drug of abuse, a medication) or another medical condition.

D. The disturbance is not better explained by the symptoms of another mental disorder (e.g., excessive worries, as in generalized anxiety disorder; preoccupation with appearance, as in body dysmorphic disorder; difficulty discarding or parting with possessions, as in hoarding disorder; hair pulling, as in trichotillomania [hair-pulling disorder]; skin picking, as in excoriation [skin-picking] disorder; stereotypies, as in stereotypic movement disorder; ritualized eating behavior, as in eating disorders; preoccupation with substances or gambling, as in substance-related and addictive disorders; preoccupation with having an illness, as in illness anxiety disorder; sexual urges or fantasies, as in paraphilic disorders; impulses, as in disruptive, impulse-control, and conduct disorders; guilty ruminations, as in major depressive disorder; thought insertion or delusional preoccupations, as in schizophrenia spectrum and other psychotic disorders; or repetitive patterns of behavior, as in autism spectrum disorder). 
OCD often begins in childhood and adolescence; several studies show an increased incidence of OCD in the ASD population, as well as increased ASD among those diagnosed with OCD (Kumar, 2012; West, 2009). Postorino et al. (2017) reported prevalence of OCD in ASD cases ranged between $2.6 \%$ and $37.2 \%$.

It can be difficult to determine an OCD diagnosis in an autistic child as there are overlapping rituals common in both diagnoses such as repetitive behavior and rigid adherence to routines (Lugnegard, Hallerback \& Gillberg, 2011; South, Ozonoff \& McMahon, 2005; Mack et al., 2010). However, the compulsions are characterized by their distressing effect on the individual and anxiety peaks as a result of the attempt to resist carrying out the compulsive behavior. Rituals of autistic patients, on the other hand, are not characterized by any preceding anxiety or distress and are often a rewarding and pleasant experience for the child.

Ruta et al. (2010) summarized the differences between children who have received a diagnosis for OCD only, ASD only, and those with a co-morbidity of OCD and ASD. They found that OCD groups and ASD groups reported different types of obsessive behaviors, with OCD children reporting higher frequencies of aggressive obsessions and checking compulsions, while ASD children displaying higher frequencies of saving/hoarding behaviours. However, they found that groups with co-morbid diagnoses, ASD with OCD or Tourette syndrome, had comparable levels of symptom severity and impairment.

Anholt et al. (2010) reported that adults with OCD show increased frequency of ADHD and autism symptoms and speculated common etiological factors to ASD, ADHD and OCD.

\section{Attention-Deficit / Hyperactivity Disorder}

Attention-Deficit / Hyperactivity Disorder (ADHD) is characterized by symptoms of inattention, hyperactivity, and impulsivity across multiple settings. Table 7 specifies the diagnostic criteria for ADHD according to the DSM 5. 
$\underline{\text { Table } 7 \text { - DSM } 5 \text { diagnostic criteria for Attention-Deficit/Hyperactivity Disorder }}$

\section{Attention-Deficit/ Hyperactivity Disorder (ADHD)}

A. Persistent pattern of inattention and/or hyperactivity-impulsivity that interferes with functioning or development, as characterized by (1) and/or (2):

1. Inattention: Six (or more) of the following symptoms have persisted for at least 6 months to a degree that is inconsistent with developmental level and that negatively impacts directly on social and academic/occupational activities.

- Often fails to give close attention to details or makes careless mistakes in schoolwork, at work, or during other activities (e.g., overlooks or misses details, work is inaccurate).

- Often has difficulty sustaining attention in tasks or play activities (e.g., has difficulty remaining focused during lectures, conversations, or lengthy reading).

- Often does not seem to listen when spoken to directly (e.g., mind seems elsewhere, even in the absence of any obvious distraction).

- Often does not follow through on instructions and fails to finish schoolwork, chores, or duties in the workplace (e.g., starts tasks but quickly loses focus and is easily sidetracked).

- Often has difficulty organizing tasks and activities (e.g., difficulty managing sequential tasks; difficulty keeping materials and belongings in order; messy, disorganized work; has poor time management; fails to meet deadlines).

- Often avoids, dislikes, or is reluctant to engage in tasks that require sustained mental effort (e.g., schoolwork or homework; for older adolescents and adults, preparing reports, completing forms, reviewing lengthy papers).

- Often loses things necessary for tasks or activities (e.g., school materials, pencils, books, tools, wallets, keys, paperwork, eyeglasses, mobile telephones).

- Is often easily distracted by extraneous stimuli (for older adolescents and adults, may include unrelated thoughts).

- Is often forgetful in daily activities (e.g., doing chores, running errands; for older adolescents and adults, returning calls, paying bills, keeping appointments).

2. Hyperactivity and impulsivity: Six (or more) of the following symptoms have persisted for at least 6 months to a degree that is inconsistent with developmental level and that negatively impacts directly on social and academic/occupational activities.

- Often fidgets with or taps hands or feet or squirms in seat.

- Often leaves seat in situations when remaining seated is expected (e.g., leaves his or her place in the classroom, in the office or other workplace, or in other situations that require remaining in place).

- Often runs about or climbs in situations where it is inappropriate. (Note: In adolescents or adults, may be limited to feeling restless.)

- Often unable to play or engage in leisure activities quietly.

- Is often "on the go," acting as if "driven by a motor" (e.g., is unable to be or uncomfortable being still for extended time, as in restaurants, meetings; may be experienced by others as being restless or difficult to keep up with).

- Often talks excessively.

- Often blurts out an answer before a question has been completed (e.g., completes people's sentences; cannot wait for turn in conversation).

- Often has difficulty waiting his or her turn (e.g., while waiting in line).

- Often interrupts or intrudes on others (e.g., butts into conversations, games, or activities; may start using other people's things without asking or receiving permission; for adolescents and adults, may intrude into or take over what others are doing). 
B. Several inattentive or hyperactive-impulsive symptoms were present prior to age 12 years.

C. Several inattentive or hyperactive-impulsive symptoms are present in two or more settings (e.g., at home, school, or work; with friends or relatives; in other activities).

D. There is clear evidence that the symptoms interfere with, or reduce the quality of, social, academic, or occupational functioning.

E. The symptoms do not occur exclusively during the course of schizophrenia or another psychotic disorder and are not better explained by another mental disorder (e.g., mood disorder, anxiety disorder, dissociative disorder, personality disorder, substance intoxication or withdrawal).

So far, no meta-analyses have been conducted on the prevalence of ADHD in ASDs. However, ADHD was found to co-occur in as many as $30-80 \%$ of ASD cases, while the presence of ASD is estimated to be between 20 to 50\% of ADHD children (Rommelse et al., 2010; van der Meer, Oerlemans \& van Steijn, 2012; Mahajan, Bernal \& Panzer, 2012; Grzadzinski et al., 2011)

For instance, van der Meer et al. (2012) conducted a study in three groups of patients (1. ADHD plus ASD; 2. predominant ASD plus ADHD; and 3. ADHD only) and found a significantly slower identification of facial emotions in the ASD plus ADHD, and ADHD plus ASD groups when compared with ADHD-alone. Significant differences were also found in visual spatial attention, verbal attention, and working memory amongst the groups but no significant differences in inhibition and cognitive flexibility was noticed (van der Meer et al., 2012). The ADHD plus ASD and ADHD-alone groups performed significantly worse in detail-focused processing (van der Meer et al., 2012).

\section{Personality disorders (PD)}

In the DSM 5, the ten PD outlined in the DSM IV were retained and they are: paranoid personality disorder, schizoid personality disorder, schizotypal personality disorder, antisocial personality disorder, borderline personality disorder, histrionic personality, narcissistic personality disorder, avoidant personality disorder, dependent personality disorder, and obsessive-compulsive personality disorder.

However, much like autism and as opposed to schizophrenia or post-traumatic stress disorder, personality disorders are not categorical and do exist on a continuum. For this reason, the DSM 5 has put forward proposed changes for further study in a separate section. The proposed model would evaluate impairments in personality functioning, and assess five broad areas of 
pathological personality traits. This model includes only six PD as evidenced by research: antisocial, avoidant, borderline, narcissistic, obsessive-compulsive, and schizotypal.

In this vein, distinct PD are not as commonly found to be diagnosed as co-morbidities of ASD. However, certain traits like aggression, and self-injurious behavior that are symptomatic of PD like borderline personality disorder and antisocial personality disorder were prevalent ASD comorbidities (Kanne \& Mazurek, 2010; Wallace et al., 2012). While there is a correlation between aggression, self-injurious behavior, and ASD; we cannot infer a causal relationship. In fact, it is difficult to determine whether these variables affect each other distinctly or if they are manifestations of the same problem. However, as it is not possible to diagnose any PD before the age of 18, as the personality is still forming, problematic traits and behaviors should be monitored using functional analysis to identify factors that might perpetuate or reinforce the trait or behavior (Belardinelli, Raza \& Taneli, 2016).

\section{Interventional Models}

Children with ASD generally require a combination of therapies and interventions to address their individual constellation of symptoms. Approaches can be broadly categorized according to conceptual models; however, there is no uniformly agreed upon classification system. The availability of programs varies by region; access to interventions may affect the choice of programming. A systematic review found insufficient evidence to suggest that any interventional model is superior to another (Magoline, 2012). However, there is moderate evidence that greater intensity (in hours per week) and greater duration (in months) of treatment lead to better outcomes (Linstead et al., 2017).

Table 8 summarizes five interventions commonly used to treat ASD and the strengths of each therapy. 
Intervention

\section{Developmental}

Behavioral

interventions

Treatment and
Education of
Autistic and Related
Communication
Handicapped
Children (TEACCH)

Children (TEACCH)

$$
\text { Description }
$$

This therapy is applied in the client's natural setting

or in a structured environment, and includes

behavioral modification, structured teaching, and is

relationship-based. Generally, it works by

reinforcing productive behaviors and discouraging

maladaptive behaviors.

Examples of developmental behavioral interventions include: [insert names]

The TEACCH method uses Structured Teaching to

help individuals overcome areas of weakness.

Occupational
therapy

Occupational therapy is often used to address deficits

in adaptive functioning and fine motor skills that

affect academic and everyday functioning.

Generalist

(does not

identify with

one

developmental

discipline)
Type

Behavioral

and

developmental

therapy

necessary skills relevant to

the development stage

The goal is to modify the environment and to improve skills.

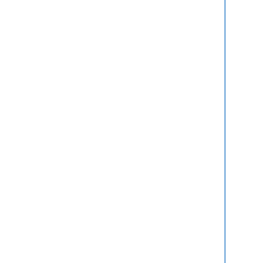

To enhance functioning inhibited by a specific deficit and to encourage selfsufficiency.
Strengths

- Targets specific domains (e.g., social, language, cognitive)

- May occur in various settings (e.g., naturalistic versus structured)

- Involves the parents, particularly when interventions are provided in the home

- Understands culture of autism

- Uses an individualized person and family-centered plan

- Organizes the physical environment

- Uses a predictable sequence of activities

- Utilizes visual schedules and visually structured activities

- Implements routines with flexibility

- Structured work/activity systems In young children with ASD, occupational therapy focuses on enhancing:

- sensory processing, sensorimotor and social-behavioral performance 


\begin{tabular}{|c|c|c|c|c|}
\hline & & & & $\begin{array}{l}\text { - } \quad \text { self-care (e.g., dressing, hygiene), } \\
\text { _ } \quad \text { participation in play. } \\
\text { In older children, the focus of } \\
\text { occupational therapy may include: } \\
\text { - } \quad \text { social and behavioral performance } \\
\text { - } \quad \text { transition to work and independence } \\
\quad \text { in the community. }\end{array}$ \\
\hline $\begin{array}{l}\text { CBT (self } \\
\text { management) }\end{array}$ & $\begin{array}{l}\text { CBT focuses on replacing negative or ineffective } \\
\text { patterns of thought and behavior with structured } \\
\text { strategies that are effective in improving mood and } \\
\text { adaptive functioning. }\end{array}$ & $\begin{array}{l}\text { Cognitive- } \\
\text { behavioral } \\
\text { therapy }\end{array}$ & $\begin{array}{l}\text { To help those with ASD } \\
\text { learn to independently } \\
\text { regulate their own behaviors } \\
\text { and act appropriately in a } \\
\text { variety of home, school, and } \\
\text { community-based situations. }\end{array}$ & $\begin{array}{l}\text { Those with ASD are taught to: } \\
-\quad \text { discriminate between appropriate and } \\
\text { inappropriate behaviors, } \\
-\quad \text { accurately monitor and record their } \\
\text { own behaviors, } \\
-\quad \text { reward themselves for behaving } \\
\text { appropriately } \\
-\quad \text { eventually take on greater } \\
\text { responsibility in their own self-care }\end{array}$ \\
\hline
\end{tabular}


4 Once a diagnosis of a co-morbidity has been ascertained, an individualized treatment plan that

5 compliments the interventions he or she is already receiving needs to be determined.

6 Comprehensive integrative models address multiple domains of function. For example, the Early

7 Start Denver Model (ESDM) uses a combination of behavioral programming and developmental-

8 and relationship-based approaches and includes parents as therapists. These types of

9 comprehensive therapies are often beneficial with co-morbid psychiatric disorders and tend to

10 directly and indirectly target symptoms that often complicate the treatment of ASD. A randomized

11 trial comparing the ESDM program with interventions commonly available in the community

12 demonstrated significant language, cognitive, and adaptive functioning gains in 48 toddlers over a

13 two-year period (Touzet et al., 2017). The Agency for Healthcare Research and Quality (AHRQ)

14 published a systematic review (2014) suggesting the utility of parent training for improving

15 behavioral outcomes in general and of adding parent training to medication interventions for

16 children with challenging behaviors. However, the studies were small, relied on parent report, and

17 used varying intervention models.

18 Nevertheless, the National Autism Center's National Standards Reports (2015) considers targeted

19 behavioral interventions to be the general standard of treatment. Historically, behavioral

20 interventions have also been found to be beneficial. A systematic review of 251 studies conducted

21 between 1980 and 1996 of targeted behavioral interventions found that focal behavioral

22 interventions consistently result in positive behavioral outcomes across a wide range of targets,

23 including aberrant behaviors (e.g., self-injury, aggression), language skills, daily living skills,

24 social skills, etc. (Matson et al., 1996).

25 On the other hand, a 2014 systematic review of studies published after 2000 suggested the efficacy 26 of CBT interventions in reducing anxiety symptoms in individuals with ASD and IQ scores above

2770 (Weitlauf et al, 2014). Moreover, a systematic review published by the US

28 Massachusetts National Standards projects, classified CBT as an established intervention for

29 children and adolescents (National Autism Center, 2015). Similarly, a meta-analysis of 12 studies

30 for anxiety co-morbidity involving 511 youth with high functioning ASD found statistically

31 significant pooled treatment effect for CBT with significant IQ heterogeneity (Ung, 2015). 
32 A systematic review (Kose, Fox \& Storch, 2018) evaluating the efficacy of CBT on ASD and OCD

33 co-morbidities found that although CBT with various modifications has been shown to be

34 beneficial, the research includes small populations and a variety of nonstandard modifications; the

35 lack of standardization in applying CBT limits the generalizability of the findings. Nevertheless,

36 all the studies did show at least some treatment gains despite the variation in age and severity of

37 diagnosis. The methods involved in the studies, while varied, generally included: mapping,

38 cognitive restructuring, fear hierarchy development, [exposure and response prevention], and

39 relapse prevention.

40 With a co-morbid diagnosis of ASD and ADHD, non-pharmacological treatments found to be

41 moderately effective include: dietary interventions (restricted elimination diets, artificial food

42 color exclusions, and free fatty acid supplementation), behavioral interventions, cognitive training,

43 and neurofeedback (Daley et al., 2014).

44 It is likely that comorbid emotional or behavioral problems would influence outcomes of social 45 skills interventions. In a study observing the effect of a social skills training program, it was 46 reported that social skills improved for children with ASD, and children with ASD and comorbid 47 anxiety, but that there was no improvement among children with ASD and comorbid ADHD, 48 highlighting the importance of individualizing treatment plans for different co-morbid diagnoses 49 (Antshel et al., 2011).

\section{Quality of Life (QoL)}

51 In the simplest terms, QoL is defined as: inner subjective personal satisfaction across 4 basic 52 domains; physical, emotional, social and vocational (Frisch, 2006). QoL interventions from a 53 positive psychology point of view, aim at promoting a life satisfaction in which humans identify, 54 pursue, and fulfill their most cherished goals, desires and wishes across all valued areas of life 55 (Toghyani et al., 2011). In the context of ASD, QoL Clinical Practice (QoLCP) normalizes the life of 56 patients and their families so that it does not fall below a predetermined cutoff threshold (Morsi 57 et al., 2016). 
58 With this definition, QoL Clinical Practice could be a precise patient and family centered care

59 method for measuring improvement, monitoring ASD symptoms, optimizing interventions and

60 personalizing medico-social care amongst individuals with ASD.

\section{- CASIO Rubric}

63 QoL provides a rubric model for life satisfaction (Change in $\underline{\text { Circumstances, } \underline{A} t t i t u d e, ~ S t a n d a r d s,}$

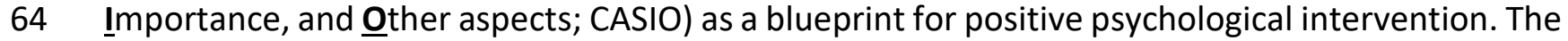

65 model presented in Figure 1 offers a strategy for management of 16 areas of life over 8 66 therapeutic sessions (Frisch, 2006, Toghyani et al., 2011). The program (illustrated in Table 9)

67 starts with introducing clinical participants and each session consists of reviews, discussions and 68 assigning of homework steps.

69 Figure 1: CASIO model for life satisfaction

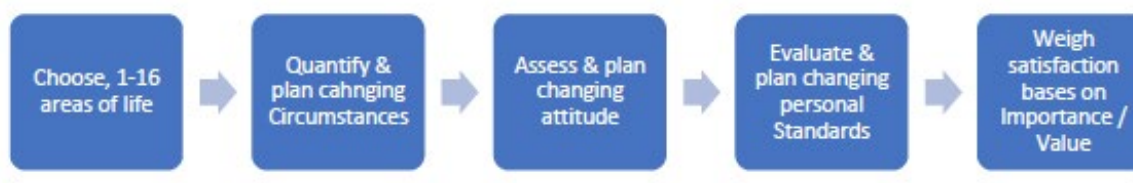

71 Table 9 - CASIO 8 session program for improving QoL

\begin{tabular}{|c|l|c|l|}
\hline \multicolumn{2}{|c|}{ Session 1 } & \multicolumn{2}{c|}{ Session 5 } \\
\hline Introduce participants & Review & $\begin{array}{l}\text { CASIO model in Values } \\
\text { Homework }\end{array}$ \\
\hline Discuss & $\begin{array}{l}\text { Goals } \\
\text { QoL interventions and rationale } \\
\text { Difficult areas }\end{array}$ & Discuss & $\begin{array}{l}\text { Relationships and its role in } \\
\text { life satisfaction }\end{array}$ \\
\hline Homework & Think how to improve QoL & Homework & $\begin{array}{l}\text { Everyday life skills: Enhance } \\
\text { relationships using writing a } \\
\text { letter and basket of eggs } \\
\text { techniques (Frisch, 2006) }\end{array}$ \\
\hline
\end{tabular}




\begin{tabular}{|c|c|c|c|}
\hline \multicolumn{2}{|r|}{ Session 2} & \multicolumn{2}{|r|}{ Session 6} \\
\hline Review & $\begin{array}{l}\text { QoL progress. } \\
\text { Homework }\end{array}$ & Review & $\begin{array}{l}\text { CASIO model in relationships. } \\
\text { Homework }\end{array}$ \\
\hline Discuss & $\begin{array}{l}\text { Role of self-esteem in happiness } \\
\text { increasing and present skills in } \\
\text { these areas }\end{array}$ & Discuss & $\begin{array}{l}\text { The role of play and leisure in } \\
\text { increasing happiness }\end{array}$ \\
\hline Homework & $\begin{array}{l}\text { Everyday life skills: Improve } \\
\text { strengths and gratitude through } \\
\text { BAT (Blessings, Accomplishments, } \\
\text { Talents and Traits) technique } \\
\text { (Frisch, 2006) }\end{array}$ & Homework & $\begin{array}{l}\text { Everyday life skills: Increase } \\
\text { play and family recreation } \\
\text { time (Frisch, 2006) }\end{array}$ \\
\hline
\end{tabular}

\begin{tabular}{|l|l|c|l|}
\hline \multicolumn{2}{|c|}{ Session 3 } & \multicolumn{2}{c|}{ Session 7 } \\
\hline Review & $\begin{array}{l}\text { CASIO model in self-esteem. } \\
\text { Homework }\end{array}$ & Review & $\begin{array}{l}\text { CASIO model of Play. } \\
\text { Homework }\end{array}$ \\
\hline Discuss & Health topics and concerns & Discuss & Learning and skills \\
\hline Homework & $\begin{array}{l}\text { Everyday life skills: Report on } \\
\text { frequent health concerns using } \\
\text { Trigger, Actions and } \\
\text { Consequences (TAC) technique } \\
\text { (Frisch, 2006) }\end{array}$ & Homework & $\begin{array}{l}\text { Everyday life skills: Boost } \\
\text { learning satisfaction using } \\
\text { problem solving technique } \\
\text { (Frisch, 2006) }\end{array}$ \\
\hline
\end{tabular}

\begin{tabular}{|l|l|c|l|}
\hline \multicolumn{2}{|c|}{ Session 4 } & \multicolumn{2}{c|}{ Session 8 } \\
\hline Review & $\begin{array}{l}\text { CASIO model in health concerns. } \\
\text { Homework. }\end{array}$ & Review & $\begin{array}{l}\text { CASIO model of learning. } \\
\text { Homework. } \\
\text { All treatment sessions. }\end{array}$ \\
\hline Discuss & Goals and important values & Discuss & $\begin{array}{l}\text { Transition to being own QoL } \\
\text { therapist and using relapse } \\
\text { prevention techniques }\end{array}$ \\
\hline Homework & $\begin{array}{l}\text { Everyday life skills: Tweak goals } \\
\text { and values using Daily Action Plan } \\
\text { (DAP) and Life Script techniques } \\
\text { (Frisch, 2006) }\end{array}$ & Homework & $\begin{array}{l}\text { Further study and work in } \\
\text { QoL }\end{array}$ \\
\hline
\end{tabular}

\section{Constructive Mode Activation for ASD Co-morbidities}

73 The QoLCP also provides patients access to constructive cognitive creation of life satisfaction and

74 happiness through the above CASIO model. Individual differences in relation to life satisfaction is

75 accommodated via recognition of interaction between external life conditions and patients' own

76 circumstances, personal values attached to life goals, and personal standards for reaching goals 
77 in 16 areas of life (Toghyani et al., 2011). Table 10 highlights definitions of the 16 areas of life

78 focused on in QoLCP.

79 Table 10 - 16 areas of life for QoLCP; adapted with minimal modifications from Frisch, 2006

1. Health is being physically fit, not sick, and without pain or disability.

2. Self-Esteem means liking and respecting yourself in light of your strengths and weaknesses, successes and failures, and ability to handle problems.

3. Goals-and-Values \pm Spiritual Life: are beliefs about what matters most in life and how you should live, both now and in the future.

4. Money (or Standard of Living) is made of the money you earn, the things you own (like a car or furniture), and believing that you will have the money and things that you need in the future.

5. Work means your career or how you spend most of your time.

6. Play (or Recreation) means what you do in your free time to relax, have fun, or improve yourself. This could include watching movies, visiting friends, or pursuing a hobby like sports or gardening.

7. Learning means gaining new skills or information about things that interest you. Learning can come from reading books or taking classes on subjects like history, car repair, or using a computer.

8. Creativity is using your imagination to come up with new and clever ways to solve every day problems or to pursue a hobby like painting, photography, or needlework. This can include decorating your home, playing the guitar, or finding a new way to solve a problem at work.

9. Helping (Social Service and Civic Action) means helping others (not just friends or relatives) in need or helping to make your community a better place to live.

10. Love (or Love Relationship) is a very close romantic relationship with another person. Love usually includes sexual feelings and feeling loved, cared for, and understood.

11. Friends (or Friendships) are people (not relatives) you know well and care about who have interests and opinions like yours.

12. Children includes a measure of how you get along with your child (or children). Think of how you get along as you care for, visit, or play with your child (or children).

13. Relatives means how you get along with your parents, grandparents, brothers, sisters, aunts, uncles, and in-laws.

14. Home is where you live. It is your house or apartment and the yard around it.

15. Neighborhood is the area around your home.

16. Community is the whole city, town, or rural area where you live (not just your neighborhood).

Community includes how nice the area looks, the amount of crime, and how well you like the people. It also includes places to go for fun like parks, concerts, sporting events, and restaurants. 
82 As the QoL of autistic patients and their families is lower than for the general population

83 (Mason et al., 2018), it requires innovative practice in addition to these 2 conventional key

84 features. The traditional QoL / psychological diagnosis of autistic patients and associated co-

85 morbidities involve medical and psychological history taking, mental state examination and 86 psychological screening. The end result of such process is a subjective diagnosis of the case and

87 the difficulties that families might be going through as a result of the disorder. Recently, these

88 subjective projections of health care practitioners are being challenged and pursuing objective

89 non biased assessment tools are being pursued (Morsi et al., 2018). This represents a key

90 requirement in personalizing QoL management of patients and families and optimizing their

91 well-being in several domains of the 16 areas of life of the CASIO model.

\section{- Assessment of QoL in ASD patients}

93 If the assessment is carried out by a QoL practitioner who is not a physician, he or she interacts

94 with the primary physician to get a medical report and a green light to carry out the QoL

95 interventions (Frisch, 2006). However, if a physician is carrying out the intervention, then QoL

96 assessment followed by a psychiatric ASD assessment should be performed starting with a

97 comprehensive history taking, and physical and mental state examination. Screening tools are

98 then applied as a baseline and a follow up investigation.

\section{- Screening tools for adults:}

100 The Research Autism of the National Autistic Society of UK validated the use of Autism Specific 101 QoL survey (ASQoL) to be used alongside the World Health Organization Quality of Life - Brief 102 (WHOQoL-BREF) and World Health Organization Quality of Life (WHOQoL) disabilities modules. 103 It is used with adults to evaluate a total ASQoL score (8 items), and a score for the global item 104 (item 9) about 'autistic identity' (McConachie et al., 2018). 
106 The most commonly used instruments are the QoL battery of Varni (Varni et al., 2007, Varni et

107 al., 2001). The battery contains the Pediatric Quality of Life Inventory ${ }^{\mathrm{TM}}$ (PedsQL) and other

108 instruments to assess a wide variety of domains related to QoL, family satisfaction, and burden

109 of diseases (Ikeda et al., 2014).

110 In conclusion, ASD patients experience a specific and unique form of QoL, the normalization of

111 which is an endpoint medical care and requires a multi-disciplinary team effort that includes a

112 QoL therapist. This normalization takes place for ASD and all its associated co-morbidities

113 through the conventional and innovative QoLCP key features and it encompasses all aspects of

114 patient's life and his / her family.

\section{Pharmacotherapy}

116 While non-pharmacological treatments have been shown to be effective in treating co-morbidities

117 of ASD; a valid treatment option is medication. Pharmacotherapy should be considered when

118 symptoms of co-morbidities are extremely severe (e.g., depression or OCD), if there is severe

119 functional impairment secondary to disruptive behavior or if there is no response to behavioral

120 interventions. Moreover, as patients with ASD often undergo several hours of weekly interventions

121 to improve general functioning, it can be overwhelming to recommend further interventions for

122 their co-morbidities.

123 Interventions should be guided by evidence and appropriate treatment guidelines (West, Waldrop

$124 \&$ Brunssen, 2009). Below is a summary of medications found to be effective in treating co125 morbidities in ASD:

126 - Depression: The efficacy of selective serotonin reuptake inhibitor (SSRIs) and serotonin 127 norepinephrine reuptake inhibitor (SNRIs) in the treatment of depression and ASD has not 128 been sufficiently validated through randomized controlled trials; nonetheless, empirical 129 data support their use as indicated in neurotypical children (Posey, Erickson, Stigler, \& $130 \quad$ McDougle, 2006).

131 - Anxiety: The treatment of anxiety in children with ASD and neurotypical children is 132 similar. A multimodal approach is recommended, including modified cognitive behavioral 
therapy, with some evidence that supports its efficacy in high functioning ASD. Pharmacological data in this population is limited (Vasa, Carroll, \& Nozzolillo, 2014). Behavioral interventions should also be considered to address sensory and special education needs (White, Oswald, Ollendick, Scahill, 2009).

- OCD: Similarities between OCD and the repetitive behaviors of ASD led researchers to investigate the use of SSRIs in the autism core domain (West, 2009). In a randomized placebo-control crossover study of 44 children with ASD, SSRI (fluoxetine) was found to be beneficial in reducing repetitive behaviors in ASDs patients. The strength of evidence for the effect of other SSRIs (e.g., citalopram and escitalopram) is insufficient (McPheeters, Warren \& Sathe, 2011). The evidence indicating that medication is effective in treating similar symptoms common in both OCD and ASD.

- ADHD: Medications could be considered in the treatment of ADHD in the context of ASD (bramson, Ravan \& Wright, 2005; Ji \& Findling, 2015). Methylphenidate (Ritalin) is the most commonly used drug and is effective in reducing symptoms of inattention and hyperactivity in children with ASD, although response rates may be lower than for children with typical ADHD. Randomized control trials suggest less benefit and more side effects for ADHD plus ASD compared with ADHD alone (Research Units on Pediatric Psychopharmacology Autism Network, 2005). Methylphenidate was found to significantly improve joint attention and emotional self-regulation as well as improvement in hyperactive and impulsive behaviors. However, the results on the efficacy of amphetamines are less conclusive. Alpha-2 adrenergic agonists were also effective when dealing with ADHD/ASD comorbidities and were found to significantly improve behavioral symptoms in 62 children when compared with a placebo. Alternatively, norepinephrine reuptake inhibitor (NERI) namely, atomextine was found in two randomized controlled trials to improve ADHD symptoms. Aggression: Haloperidol, a typical neuroleptic, is commonly used to treat severe aggression in autistic children however these have been found to significantly impair movement in recipients (Miral et al., 2008). In addition risperidone was found to reduce irritability, aggression, self-injurious behaviors, and severe tantrums in ASD (Huffman, Sutcliffe, Tanner \& Feldman, 2011; McPheeters, Warren \& Sathe, 2011; McVoy \& Findling, 2009) For younger ASD cases aged between 6 to 17 years, aripiprazole is 
recommended to treat aggression and in a longitudinal study both risperidone and aripiprazole were found to adequately treat aggression and irritability in ASD patients, especially when combined with Parent Training in behavioral management (Arnold, Aman \& Li, 2012). 


\section{Conclusions and future directions}

170 Psychological comorbidities are relatively recently recognized phenomena in ASD. Although, the

171 majority of ASD have at least one comorbid psychological disorder.

172 The high level of comorbidities could be attributed to similar or associated risk factors, i.e., the

173 occurrence of one disorder increases the risk of another disorder. In addition, limitations could

174 include misdiagnosis and inadequacy of the diagnostic systems to reflect the factual nature of

175 psychiatric disorders that co-occur with an ASD diagnosis.

176 These comorbid conditions persist from childhood to adolescence to adulthood and are

177 associated with more impaired social functioning (Chang, Quan, \& Wood, 2012; Simonoff et al., 178 2013).

179 The current understanding of the processes that contribute to the high rates of comorbidities in 180 ASD remains incomplete; furthermore, there has been nearly no research on interventions 181 involving comorbid presentations in ASD with other psychological and psychiatric disorders.

182 Thus, research studies in this field is highly needed that may provide important clues about the 183 underlying mechanisms, and potential risk and protective factors involved in ASD.

184 Targeting two comprehensive modules of processes likely involved in high rates of comorbidities 185 in ASD may be mainly useful. The first class is central developmental processes directly linked to 186 the etiology of ASD, while the second module includes wider, transdiagnostic risk processes. It is 187 possible that as developing social neural systems increasingly advance from 'normal' trajectories 188 in ASD children, other processes related to mental health may be affected as well.

189 In this vein, we can consider core processes such as social detachment and atypical social 190 information processing in the possible pathogenesis of comorbid conditions. As an actual 191 example, decreased hedonic responses to the social-emotional bids of others may be involved in 192 the development of oppositional problems or aggression.

193 The second class is transdiagnostic processes that are not necessarily causally linked to ASD core 194 impairments.

195 Rather, they are 'fundamental' in the sense that they are central to many forms of 196 psychopathology. There are many transdiagnostic processes, such as attentional avoidance, 197 persistent negative affect, and rumination. Poor emotion regulation, for example, is a 
transdiagnostic process that has been linked theoretically to the high rates of anxiety disorders seen in people with ASD (Mazefsky et al., 2013; White, Schry, Miyazaki, Ollendick, \& Scahill, 2014). These processes occur over the course of development and thus it will be important for future research to consider the longitudinal course of comorbidity and the possibility of sequential comorbidities over the course of a lifetime (Rutter, Kim Cohen, \& Maughan, 2006).

The early identification and treatment of the psychological comorbidities are useful for symptom relief, quality of life and daily adaptive functioning.

However, it is also similarly important that comorbid conditions do not take clinical attention away from core/primary ASD symptoms in need of intervention.

Previous studies on ASD and their comorbidities used different criteria and assessment tools completed by different informants (e.g., parents, teachers, practitioners/clinicians or self-report), resulting in different diagnoses and comorbidity results. Thus, further research and efforts should concentrate on comprehensive standardized diagnostic methods and assessments for ASD and psychiatric and psychological comorbidities. Furthermore, some ASD impairments overlap with some of the features of comorbid disorders, making it difficult to differentiate between them. For example, OCD diagnosis and ASD impairments have overlapping rituals in common. These include repetitive behaviour and rigid adherence to routines. However, whilst OCD compulsions are characterized by distress and anxiety, similar rituals of autistic patients are often a rewarding and pleasant experience for the child and free of such anxiety and distress. Thus, assessment tools should have the ability to distinguish clearly between pure ASD and ASD and its comorbidities. In some cases, it may be difficult to extract information for self-reports from ASD patients (e.g. self-report of feelings and how those feelings impact daily functioning) due to inherent impairments in social interaction and verbal communication. This can result in a diagnosis being missed and the patient not receiving helpful interventions.

Cognitive Behavioural Therapy (CBT) has been shown to be effective in treating ASD and some of its comorbidities, however, research was limited. These limitations included small population size, a lack of standardization in applying CBT, and the neglect of ASD comorbidities and/or 
227 different outcomes for different comorbidities of ASD (e.g., improvement in some but not for 228 others). This highlights the importance of individualizing treatment plans for different co-morbid 229 diagnoses.

230 In conclusion, improved comprehensive assessment diagnostic tools taking into account various 231 comorbidities and how they relate to ASD are needed. Once accurate diagnoses have been made, 232 better individualized and comprehensive interventions should be constructed to yield optimum 233 outcomes for patients. 
236

237

238

239

240

241

242

243

244

245

246

247

248

249

250

251

252

253

254

255

256

257

258

259

260

261

262

263

264

265

266

267

268

269

270

Abramson, R. K., Ravan, S. A., Wright, H. H., Wieduwilt, K., Wolpert, C. M., Donnelly, S. A., ... Cuccaro, M. L. (2005). The relationship between restrictive and repetitive behaviors in individuals with autism and obsessive compulsive symptoms in parents. Child Psychiatry Hum Dev, 36(2), 155 165. Retrieved from http://dx.doi.org/10.1007/s10578-005-2973-7. doi:10.1007/s10578-0052973-7

Amr, M., Bu Ali, W., Hablas, H., Raddad, D., El-Mehesh, F., El-Gilany, A. H., \& Al-Shamy, H. (2012). Sociodemographic factors in Arab children with Autism Spectrum Disorders. Pan Afr Med J, 13, 65. Retrieved from http://dx.doi.org/.

Anholt, G. E., Cath, D. C., van Oppen, P., Eikelenboom, M., Smit, J. H., van Megen, H., \& van Balkom, A. J. (2010). Autism and ADHD symptoms in patients with OCD: are they associated with specific OC symptom dimensions or OC symptom severity? J Autism Dev Disord, 40(5), 580-589. Retrieved from http://dx.doi.org/10.1007/s10803-009-0922-1. doi:10.1007/s10803-009-0922-1

Arnold, L. E., Aman, M. G., Li, X., Butter, E., Humphries, K., Scahill, L., . . Stigler, K. A. (2012). RUPP AUTISM NETWORK RANDOMIZED CLINICAL TRIAL OF PARENT TRAINING AND MEDICATION: ONE-YEAR FOLLOW-UP. J Am Acad Child Adolesc Psychiatry, 51(11), 1173-1184. Retrieved from http://dx.doi.org/10.1016/j.jaac.2012.08.028.doi:10.1016/j.jaac.2012.08.028

Barnhill, G. P., \& Myles, B. S. (2001). Attributional Style and Depression in Adolescents with Asperger Syndrome:. http://dx.doi.org/10.1177/109830070100300305. Retrieved from https://journals.sagepub.com/doi/abs/10.1177/109830070100300305?journalCode=pbia. doi:10.1177_109830070100300305

Belardinelli, C., Raza, M., \& Taneli, T. (2016). Comorbid Behavioral Problems and Psychiatric Disorders in Autism Spectrum Disorders. Journal of Childhood \& Developmental Disorders, 2-11.

Bellini, S. (2004). Social Skill Deficits and Anxiety in High-Functioning Adolescents With Autism Spectrum Disorders:. http://dx.doi.org/10.1177/10883576040190020201. Retrieved from https://journals.sagepub.com/doi/abs/10.1177/10883576040190020201. doi:10.1177_10 883576040190020201

Bradley, E. A., Summers, J. A., Wood, H. L., \& Bryson, S. E. (2004). Comparing rates of psychiatric and behavior disorders in adolescents and young adults with severe intellectual disability with and without autism. J Autism Dev Disord, 34(2), 151-161. Retrieved from http://dx.doi.org/.

Brereton, A. V., Tonge, B. J., \& Einfeld, S. L. (2006). Psychopathology in children and adolescents with autism compared to young people with intellectual disability. J Autism Dev Disord, 36(7), 863870. Retrieved from http://dx.doi.org/10.1007/s10803-006-0125-y. doi:10.1007/s10803-006$0125-\mathrm{y}$

Cassidy, S., Bradley, P., Robinson, J., Allison, C., McHugh, M., \& Baron-Cohen, S. (2014). Suicidal ideation and suicide plans or attempts in adults with Asperger's syndrome attending a specialist 
diagnostic clinic: a clinical cohort study. Lancet Psychiatry, 1(2), 142-147. Retrieved from http://dx.doi.org/10.1016/s2215-0366(14)70248-2. doi:10.1016/s2215-0366(14)70248-2

Chandrasekhar, T., \& Sikich, L. (2015). Challenges in the diagnosis and treatment of depression in autism spectrum disorders across the lifespan. Dialogues Clin Neurosci, 17(2), 219-227. Retrieved from http://dx.doi.org/.

Chez, M. G., Burton, Q., Dowling, T., Chang, M., Khanna, P., \& Kramer, C. (2007). Memantine as adjunctive therapy in children diagnosed with autistic spectrum disorders: an observation of initial clinical response and maintenance tolerability. J Child Neurol, 22(5), 574-579. Retrieved from http://dx.doi.org/10.1177/0883073807302611.doi:10.1177/0883073807302611

Crane, L., Chester, J. W., Goddard, L., Henry, L. A., \& Hill, E. (2016). Experiences of autism diagnosis: A survey of over 1000 parents in the United Kingdom. Autism, 20(2), 153-162. Retrieved from http://dx.doi.org/10.1177/1362361315573636. doi:10.1177/1362361315573636

Daley, D., van der Oord, S., Ferrin, M., Danckaerts, M., Doepfner, M., Cortese, S., \& Sonuga-Barke, E. J. (2014). Behavioral interventions in attention-deficit/hyperactivity disorder: a meta-analysis of randomized controlled trials across multiple outcome domains. J Am Acad Child Adolesc Psychiatry, 53(8), 835-847,. Retrieved from http://dx.doi.org/10.1016/j.jaac.2014.05.013. doi:10.1016/j.jaac.2014.05.013

de Bruin, E. I., Ferdinand, R. F., Meester, S., de Nijs, P. F., \& Verheij, F. (2007). High rates of psychiatric co-morbidity in PDD-NOS. J Autism Dev Disord, 37(5), 877-886. Retrieved from http://dx.doi.org/10.1007/s10803-006-0215-x.doi:10.1007/s10803-006-0215-x

Evans, D. W., Canavera, K., Kleinpeter, F. L., Maccubbin, E., \& Taga, K. (2005). The fears, phobias and anxieties of children with autism spectrum disorders and Down syndrome: comparisons with developmentally and chronologically age matched children. Child Psychiatry Hum Dev, 36(1), 326. Retrieved from http://dx.doi.org/10.1007/s10578-004-3619-x. doi:10.1007/s10578-004$3619-x$

Frenz, D. (2016). Diagnostic Comorbidity in DSM-5: Origins, Current Status, and Potential Solutions. Retrieved from https://pro.psychcentral.com/diagnostic-comorbidity-in-dsm-5-origins-currentstatus-and-potential-solutions/.

Frisch, M. (2005). Quality of Life Therapy: Applying a Life Satisfaction Approach to Positive Psychology and Cognitive Therapy.

Gadow, K. D., Devincent, C. J., Pomeroy, J., \& Azizian, A. (2005). Comparison of DSM-IV symptoms in elementary school-age children with PDD versus clinic and community samples. Autism, 9(4), 392-415. Retrieved from http://dx.doi.org/10.1177/1362361305056079. doi:10.1177/1362361305056079

Ghaziuddin, M., Alessi, N., \& Greden, J. F. (1995). Life events and depression in children with pervasive developmental disorders. J Autism Dev Disord, 25(5), 495-502. Retrieved from http://dx.doi.org/. 
Ghaziuddin, M., Ghaziuddin, N., \& Greden, J. (2002). Depression in persons with autism: implications for research and clinical care. J Autism Dev Disord, 32(4), 299-306. Retrieved from http://dx.doi.org/.

Ghaziuddin, M., \& Greden, J. (1998). Depression in children with autism/pervasive developmental disorders: a case-control family history study. J Autism Dev Disord, 28(2), 111-115. Retrieved from http://dx.doi.org/.

Gillott, A., \& Standen, P. J. (2007). Levels of anxiety and sources of stress in adults with autism. J Intellect Disabil, 11(4), 359-370. Retrieved from http://dx.doi.org/10.1177/1744629507083585. doi:10.1177/1744629507083585

Goel, R., Hong, J. S., Findling, R. L., \& Ji, N. Y. (2018). An update on pharmacotherapy of autism spectrum disorder in children and adolescents. Int Rev Psychiatry, 30(1), 78-95. Retrieved from http://dx.doi.org/10.1080/09540261.2018.1458706. doi:10.1080/09540261.2018.145870 6

Gotham, K., Unruh, K., \& Lord, C. (2015). Depression and its measurement in verbal adolescents and adults with autism spectrum disorder. Autism, 19(4), 491-504. Retrieved from http://dx.doi.org/10.1177/1362361314536625.doi:10.1177/1362361314536625

Green, J., Gilchrist, A., Burton, D., \& Cox, A. (2000). Social and psychiatric functioning in adolescents with Asperger syndrome compared with conduct disorder. J Autism Dev Disord, 30(4), 279-293. Retrieved from http://dx.doi.org/.

Grzadzinski, R., Di Martino, A., Brady, E., Mairena, M. A., O'Neale, M., Petkova, E., . . Castellanos, F. X. (2011). Examining autistic traits in children with ADHD: does the autism spectrum extend to ADHD? J Autism Dev Disord, 41(9), 1178-1191. Retrieved from http://dx.doi.org/10.1007/s10803-010-1135-3. doi:10.1007/s10803-010-1135-3

Hedley, D., \& Young, R. (2006). Social comparison processes and depressive symptoms in children and adolescents with Asperger syndrome. Autism, 10(2), 139-153. Retrieved from http://dx.doi.org/10.1177/1362361306062020.doi:10.1177/1362361306062020

Hofvander, B., Delorme, R., Chaste, P., Nyden, A., Wentz, E., Stahlberg, O., . . Leboyer, M. (2009). Psychiatric and psychosocial problems in adults with normal-intelligence autism spectrum disorders. BMC Psychiatry, 9, 35. Retrieved from http://dx.doi.org/10.1186/1471-244x-935. doi:10.1186/1471-244x-9-35

Hollander, E., Phillips, A. T., \& Yeh, C. C. (2003). Targeted treatments for symptom domains in child and adolescent autism. Lancet, 362(9385), 732-734. Retrieved from http://dx.doi.org/10.1016/s0140-6736(03)14236-5.doi:10.1016/s0140-6736(03)14236-5

Huffman, L. C., Sutcliffe, T. L., Tanner, I. S., \& Feldman, H. M. (2011). Management of symptoms in children with autism spectrum disorders: a comprehensive review of pharmacologic and complementary-alternative medicine treatments. J Dev Behav Pediatr, 32(1), 56-68. Retrieved from http://dx.doi.org/10.1097/DBP.0b013e3182040acf.doi:10.1097/DBP.0b013e3182040acf 
Ikeda, E., Hinckson, E., \& Krageloh, C. (2014). Assessment of quality of life in children and youth with autism spectrum disorder: a critical review. Qual Life Res, 23(4), 1069-1085. Retrieved from http://dx.doi.org/10.1007/s11136-013-0591-6. doi:10.1007/s11136-013-0591-6

Joshi, G., Wozniak, J., Petty, C., Martelon, M. K., Fried, R., Bolfek, A., . . Biederman, J. (2013). Psychiatric comorbidity and functioning in a clinically referred population of adults with autism spectrum disorders: a comparative study. J Autism Dev Disord, 43(6), 1314-1325. Retrieved from http://dx.doi.org/10.1007/s10803-012-1679-5. doi:10.1007/s10803-012-1679-5

Kim, J. A., Szatmari, P., Bryson, S. E., Streiner, D. L., \& Wilson, F. J. (2000). The Prevalence of Anxiety and Mood Problems among Children with Autism and Asperger Syndrome:. http://dx.doi.org/10.1177/1362361300004002002. Retrieved from https://journals.sagepub.com/doi/abs/10.1177/1362361300004002002. doi:10.1177_136 2361300004002002

Kose, L. K., Fox, L., \& Storch, E. A. (2018). Effectiveness of Cognitive Behavioral Therapy for Individuals with Autism Spectrum Disorders and Comorbid Obsessive-Compulsive Disorder: A Review of the Research. J Dev Phys Disabil, 30(1), 69-87. Retrieved from http://dx.doi.org/10.1007/s10882-017-9559-8. doi:10.1007/s10882-017-9559-8

Kumar, B., Prakash, A., Sewal, R. K., Medhi, B., \& Modi, M. (2012). Drug therapy in autism: a present and future perspective. Pharmacol Rep, 64(6), 1291-1304. Retrieved from http://dx.doi.org/.

Lainhart, J. E., \& Folstein, S. E. (1994). Affective disorders in people with autism: a review of published cases. J Autism Dev Disord, 24(5), 587-601. Retrieved from http://dx.doi.org/.

Leyfer, O. T., Folstein, S. E., Bacalman, S., Davis, N. O., Dinh, E., Morgan, J., . . . Lainhart, J. E. (2006). Comorbid psychiatric disorders in children with autism: interview development and rates of disorders. J Autism Dev Disord, 36(7), 849-861. Retrieved from http://dx.doi.org/10.1007/s10803-006-0123-0. doi:10.1007/s10803-006-0123-0

Lidstone, J., Uljarević, M., Sullivan, J., Rodgers, J., McConachie, H., Freeston, M., .. . Leekam, S. (2014). Relations among restricted and repetitive behaviors, anxiety and sensory features in children with autism spectrum disorders. - PsycNET. Research in Autism Spectrum Disorders, 82-92. Retrieved from https://psycnet.apa.org/record/2014-00769005. doi:10.1016/j.rasd.2013.10.001

Linstead, E., Dixon, D. R., Hong, E., Burns, C. O., French, R., Novack, M. N., \& Granpeesheh, D. (2017). An evaluation of the effects of intensity and duration on outcomes across treatment domains for children with autism spectrum disorder. Transl Psychiatry, 7(9), e1234. Retrieved from http://dx.doi.org/10.1038/tp.2017.207.doi:10.1038/tp.2017.207

Lugnegard, T., Hallerback, M. U., \& Gillberg, C. (2011). Psychiatric comorbidity in young adults with a clinical diagnosis of Asperger syndrome. Res Dev Disabil, 32(5), 1910-1917. Retrieved from http://dx.doi.org/10.1016/j.ridd.2011.03.025. doi:10.1016/j.ridd.2011.03.025 
Lundstrom, S., Reichenberg, A., Melke, J., Rastam, M., Kerekes, N., Lichtenstein, P., . . Anckarsater, H. (2015). Autism spectrum disorders and coexisting disorders in a nationwide Swedish twin study. J Child Psychol Psychiatry, 56(6), 702-710. Retrieved from http://dx.doi.org/10.1111/icpp.12329. doi:10.1111/jcpp.12329

Mack, H., Fullana, M. A., Russell, A. J., Mataix-Cols, D., Nakatani, E., \& Heyman, I. (2010). Obsessions and compulsions in children with Asperger's syndrome or high-functioning autism: a casecontrol study. Aust N Z J Psychiatry, 44(12), 1082-1088. Retrieved from http://dx.doi.org/10.3109/00048674.2010.515561. doi:10.3109/00048674.2010.515561

Maglione, M. A., Gans, D., Das, L., Timbie, J., \& Kasari, C. (2012). Nonmedical interventions for children with ASD: recommended guidelines and further research needs. Pediatrics, 130 Suppl 2, S169178. Retrieved from http://dx.doi.org/10.1542/peds.2012-09000. doi:10.1542/peds.201209000

Magnuson, K. M., \& Constantino, J. N. (2011). Characterization of depression in children with autism spectrum disorders. J Dev Behav Pediatr, 32(4), 332-340. Retrieved from http://dx.doi.org/10.1097/DBP.0b013e318213f56c.doi:10.1097/DBP.0b013e318213f56c

Mahajan, R., Bernal, M. P., Panzer, R., Whitaker, A., Roberts, W., Handen, B., . . VeenstraVanderWeele, J. (2012). Clinical practice pathways for evaluation and medication choice for attention-deficit/hyperactivity disorder symptoms in autism spectrum disorders. Pediatrics, 130 Supp/ 2, S125-138. Retrieved from http://dx.doi.org/10.1542/peds.20120900J. doi:10.1542/peds.2012-0900J

Mason, D., McConachie, H., Garland, D., Petrou, A., Rodgers, J., \& Parr, J. R. (2018). Predictors of quality of life for autistic adults. Autism Res, 11(8), 1138-1147. Retrieved from http://dx.doi.org/10.1002/aur.1965. doi:10.1002/aur.1965

Matson, J. L., Benavidez, D. A., Compton, L. S., Paclawskyj, T., \& Baglio, C. (1996). Behavioral treatment of autistic persons: a review of research from 1980 to the present. Res Dev Disabil, 17(6), 433465. Retrieved from http://dx.doi.org/.

Mattila, M. L., Hurtig, T., Haapsamo, H., Jussila, K., Kuusikko-Gauffin, S., Kielinen, M., . . Moilanen, I. (2010). Comorbid psychiatric disorders associated with Asperger syndrome/high-functioning autism: a community- and clinic-based study. J Autism Dev Disord, 40(9), 1080-1093. Retrieved from http://dx.doi.org/10.1007/s10803-010-0958-2.doi:10.1007/s10803-010-0958-2

Mazefsky, C. A., Oswald, D. P., Day, T. N., Eack, S. M., Minshew, N. J., \& Lainhart, J. E. (2012). ASD, a psychiatric disorder, or both? Psychiatric diagnoses in adolescents with high-functioning ASD. $J$ Clin Child Adolesc Psychol, 41(4), 516-523. Retrieved from http://dx.doi.org/10.1080/15374416.2012.686102. doi:10.1080/15374416.2012.686102

Mazurek, M. O., \& Kanne, S. M. (2010). Friendship and internalizing symptoms among children and adolescents with ASD. J Autism Dev Disord, 40(12), 1512-1520. Retrieved from http://dx.doi.org/10.1007/s10803-010-1014-y.doi:10.1007/s10803-010-1014-y 
Mazzone, L., Postorino, V., De Peppo, L., Fatta, L., Lucarelli, V., Reale, L., . . Vicari, S. (2013). Mood symptoms in children and adolescents with autism spectrum disorders. Res Dev Disabil, 34(11), 3699-3708. Retrieved from http://dx.doi.org/10.1016/i.ridd.2013.07.034. doi:10.1016/j.ridd.2013.07.034

McConachie, H., Mason, D., Parr, J. R., Garland, D., Wilson, C., \& Rodgers, J. (2018). Enhancing the Validity of a Quality of Life Measure for Autistic People. J Autism Dev Disord, 48(5), 1596-1611. Retrieved from http://dx.doi.org/10.1007/s10803-017-3402-z. doi:10.1007/s10803-017-3402-z

McPheeters, M. L., Warren, Z., Sathe, N., Bruzek, J. L., Krishnaswami, S., Jerome, R. N., \& VeenstraVanderweele, J. (2011). A systematic review of medical treatments for children with autism spectrum disorders. Pediatrics, 127(5), e1312-1321. Retrieved from http://dx.doi.org/10.1542/peds.2011-0427. doi:10.1542/peds.2011-0427

McVoy, M., \& Findling, R. (2009). Child and adolescent psychopharmacology update. Psychiatr Clin North Am, 32(1), 111-133. Retrieved from http://dx.doi.org/10.1016/i.psc.2008.11.002. doi:10.1016/j.psc.2008.11.002

Miral, S., Gencer, O., Inal-Emiroglu, F. N., Baykara, B., Baykara, A., \& Dirik, E. (2008). Risperidone versus haloperidol in children and adolescents with $A D$ : a randomized, controlled, double-blind trial. Eur Child Adolesc Psychiatry, 17(1), 1-8. Retrieved from http://dx.doi.org/10.1007/s00787007-0620-5. doi:10.1007/s00787-007-0620-5

MORSI, H., CLARK, H., \& TODOROVIC, N. (2018). Advances in developmental psychology and subjective vs objective patient and family centred QoL care â?? DIFI. Retrieved from https://www.difi.org.qa/presentations/advances-in-developmental-psychology-andsubjective-vs-objective-patient-and-family-centred-qol-care/

MORSI, H., PERKINS, J. D., ALSAIED, A., HASSAN, A., LANGFORD, C., ALEMAYEHU, E., . . ABULABAN, M. (2016). Understanding the Quality of Life (QoL) and Quality Adjusted Survival (QAS) in Children, Teens, and Young Adults with Cancer. International Journal of Advanced Biomedicine, 1, 29-31. Retrieved from https://www.researchgate.net/publication/308031344 Understanding the Quality of Li fe QoL and Quality Adjusted Survival QAS in Children Teens and Young Adults with Can cer.doi:http://dx.doi.org/

Munesue, T., Ono, Y., Mutoh, K., Shimoda, K., Nakatani, H., \& Kikuchi, M. (2008). High prevalence of bipolar disorder comorbidity in adolescents and young adults with high-functioning autism spectrum disorder: a preliminary study of 44 outpatients. J Affect Disord, 111(2-3), 170-175. Retrieved from http://dx.doi.org/10.1016/j.jad.2008.02.015.doi:10.1016/j.jad.2008.02.015

Muris, P., Steerneman, P., Merckelbach, H., Holdrinet, I., \& Meesters, C. (1998). Comorbid anxiety symptoms in children with pervasive developmental disorders. J Anxiety Disord, 12(4), 387-393. Retrieved from http://dx.doi.org/.

Myers, K., \& Winters, N. C. (2002). Ten-year review of rating scales. II: Scales for internalizing disorders. J Am Acad Child Adolesc Psychiatry, 41(6), 634-659. Retrieved 
Network., R. U. o. P. P. A. (2005). Randomized, controlled, crossover trial of methylphenidate in pervasive developmental disorders with hyperactivity. Arch Gen Psychiatry, 62(11), 1266-1274. Retrieved from http://dx.doi.org/10.1001/archpsyc.62.11.1266. doi:10.1001/archpsyc.62.11.1266

Posey, D. J., Erickson, C. A., Stigler, K. A., \& McDougle, C. J. (2006). The use of selective serotonin reuptake inhibitors in autism and related disorders. J Child Adolesc Psychopharmacol, 16(1-2), 181-186. Retrieved from http://dx.doi.org/10.1089/cap.2006.16.181. doi:10.1089/cap.2006.16.181

Postorino, V., Sharp, W. G., McCracken, C. E., Bearss, K., Burrell, T. L., Evans, A. N., \& Scahill, L. (2017). A Systematic Review and Meta-analysis of Parent Training for Disruptive Behavior in Children with Autism Spectrum Disorder. Clin Child Fam Psychol Rev, 20(4), 391-402. Retrieved from http://dx.doi.org/10.1007/s10567-017-0237-2.doi:10.1007/s10567-017-0237-2

Pouw, L., Rieffe, C., Stockmann, L., \& Gadow, K. (2013). The link between emotion regulation, social functioning, and depression in boys with ASD. - PsycNET. Research in Autism Spectrum Disorders, 549-556. Retrieved from https://psycnet.apa.org/record/2013-07990007. doi:10.1016/j.rasd.2013.01.002

Rommelse, N. N. J., Franke, B., Geurts, H. M., Hartman, C. A., \& Buitelaar, J. K. (2010). Shared heritability of attention-deficit/hyperactivity disorder and autism spectrum disorder. Eur Child Adolesc Psychiatry, 19(3), 281-295. Retrieved from http://dx.doi.org/10.1007/s00787-0100092-x. doi:10.1007/s00787-010-0092-x

Rosenberg, R., Kaufmann, W., Law, K., \& Law, P. (2011). Parent Report of Community Psychiatric Comorbid Diagnoses in Autism Spectrum Disorders. Autism Research and Treatment, 1-10. Retrieved from https://www.researchgate.net/publication/230769980 Parent Report of Community P sychiatric Comorbid Diagnoses in Autism Spectrum Disorders.doi:http://dx.doi.org/10.1155 /2011/405849

Ruta, L., Mugno, D., D'Arrigo, V. G., Vitiello, B., \& Mazzone, L. (2010). Obsessive-compulsive traits in children and adolescents with Asperger syndrome. Eur Child Adolesc Psychiatry, 19(1), 17-24. Retrieved from http://dx.doi.org/10.1007/s00787-009-0035-6. doi:10.1007/s00787-009-0035-6

Simonoff, E. (2012). Autism spectrum disorder: prevalence and cause may be bound together. Br J Psychiatry, 201, 88-89. Retrieved from http://dx.doi.org/10.1192/bjp.bp.111.104703. doi:10.1192/bjp.bp.111.104703

Simonoff, E., Pickles, A., Charman, T., Chandler, S., Loucas, T., \& Baird, G. (2008). Psychiatric disorders in children with autism spectrum disorders: prevalence, comorbidity, and associated factors in a population-derived sample. J Am Acad Child Adolesc Psychiatry, 47(8), 921-929. Retrieved from http://dx.doi.org/10.1097/CHI.0b013e318179964f.doi:10.1097/CHI.0b013e318179964f 
494

South, M., Ozonoff, S., \& McMahon, W. M. (2005). Repetitive behavior profiles in Asperger syndrome and high-functioning autism. J Autism Dev Disord, 35(2), 145-158. Retrieved from http://dx.doi.org/.

Stahlberg, O., Soderstrom, H., Rastam, M., \& Gillberg, C. (2004). Bipolar disorder, schizophrenia, and other psychotic disorders in adults with childhood onset $\mathrm{AD} / \mathrm{HD}$ and/or autism spectrum disorders. J Neural Transm (Vienna), 111(7), 891-902. Retrieved from http://dx.doi.org/10.1007/s00702-004-0115-1. doi:10.1007/s00702-004-0115-1

Sterling, L., Dawson, G., Estes, A., \& Greenson, J. (2008). Characteristics associated with presence of depressive symptoms in adults with autism spectrum disorder. J Autism Dev Disord, 38(6), 1011-1018. Retrieved from http://dx.doi.org/10.1007/s10803-007-0477-y. doi:10.1007/s10803007-0477-y

Stewart, M. E., Barnard, L., Pearson, J., Hasan, R., \& O'Brien, G. (2006). Presentation of depression in autism and Asperger syndrome: a review. Autism, 10(1), 103-116. Retrieved from http://dx.doi.org/10.1177/1362361306062013.doi:10.1177/1362361306062013

Strang, J. F., Kenworthy, L., Daniolos, P., Case, L., Wills, M. C., Martin, A., \& Wallace, G. L. (2012). Depression and Anxiety Symptoms in Children and Adolescents with Autism Spectrum Disorders without Intellectual Disability. Res Autism Spectr Disord, 6(1), 406-412. Retrieved from http://dx.doi.org/10.1016/j.rasd.2011.06.015.doi:10.1016/j.rasd.2011.06.015

Sukhodolsky, D. G., Scahill, L., Gadow, K. D., Arnold, L. E., Aman, M. G., McDougle, C. J., ... Vitiello, B. (2008). Parent-rated anxiety symptoms in children with pervasive developmental disorders: frequency and association with core autism symptoms and cognitive functioning. J Abnorm Child Psychol, 36(1), 117-128. Retrieved from http://dx.doi.org/10.1007/s10802-007-91659. doi:10.1007/s10802-007-9165-9

Talisa, V. B., Boyle, L., Crafa, D., \& Kaufmann, W. E. (2014). Autism and anxiety in males with fragile X syndrome: an exploratory analysis of neurobehavioral profiles from a parent survey. Am J Med Genet A, 164a(5), 1198-1203. Retrieved from http://dx.doi.org/10.1002/ajmg.a.36468. doi:10.1002/ajmg.a.36468

TOGHYANI, M., KALANTARI, M., AMIRI, S., \& MOLAVI, H. (2011). The Effectiveness of Quality of Life Therapy on Subjective Well-Being of Male Adolescents. Procedia - Social and Behavioral Sciences, 30, 1752-1757. Retrieved from https://www.researchgate.net/publication/271881266 The Effectiveness of Quality of Life Therapy on Subjective WellBeing of Male Adolescents. doi:http://dx.doi.org/10.1016/j.sbspro.2011.10.338

Touzet, S., Occelli, P., Schroder, C., Manificat, S., Gicquel, L., Stanciu, R., .. Geoffray, M. M. (2017). Impact of the Early Start Denver Model on the cognitive level of children with autism spectrum disorder: study protocol for a randomised controlled trial using a two-stage Zelen design. BMJ Open, 7(3), e014730. Retrieved from http://dx.doi.org/10.1136/bmjopen-2016014730. doi:10.1136/bmjopen-2016-014730 
Ung, D., Selles, R., Small, B. J., \& Storch, E. A. (2015). A Systematic Review and Meta-Analysis of Cognitive-Behavioral Therapy for Anxiety in Youth with High-Functioning Autism Spectrum Disorders. Child Psychiatry Hum Dev, 46(4), 533-547. Retrieved from http://dx.doi.org/10.1007/s10578-014-0494-y. doi:10.1007/s10578-014-0494-y

van der Meer, J. M., Oerlemans, A. M., van Steijn, D. J., Lappenschaar, M. G., de Sonneville, L. M., Buitelaar, J. K., \& Rommelse, N. N. (2012). Are autism spectrum disorder and attentiondeficit/hyperactivity disorder different manifestations of one overarching disorder? Cognitive and symptom evidence from a clinical and population-based sample. J Am Acad Child Adolesc Psychiatry, 51(11), 1160-1172. Retrieved from http://dx.doi.org/10.1016/j.jaac.2012.08.024. doi:10.1016/j.jaac.2012.08.024

van Steensel, F. J., Bogels, S. M., \& Perrin, S. (2011). Anxiety disorders in children and adolescents with autistic spectrum disorders: a meta-analysis. Clin Child Fam Psychol Rev, 14(3), 302-317. Retrieved from http://dx.doi.org/10.1007/s10567-011-0097-0. doi:10.1007/s10567-011-0097-0

Varni, J. W., Limbers, C., \& Burwinkle, T. M. (2007). Literature review: health-related quality of life measurement in pediatric oncology: hearing the voices of the children. J Pediatr Psychol, 32(9), 1151-1163. Retrieved from http://dx.doi.org/10.1093/jpepsy/jsm008. doi:10.1093/jpepsy/jsm008

Varni, J. W., Seid, M., \& Kurtin, P. S. (2001). PedsQL 4.0: reliability and validity of the Pediatric Quality of Life Inventory version 4.0 generic core scales in healthy and patient populations. Med Care, 39(8), 800-812. Retrieved from http://dx.doi.org/.

Vasa, R. A., Carroll, L. M., Nozzolillo, A. A., Mahajan, R., Mazurek, M. O., Bennett, A. E., .. Bernal, M. P. (2014). A systematic review of treatments for anxiety in youth with autism spectrum disorders. J Autism Dev Disord, 44(12), 3215-3229. Retrieved from http://dx.doi.org/10.1007/s10803-014-2184-9. doi:10.1007/s10803-014-2184-9

Vickerstaff, S., Heriot, S., Wong, M., Lopes, A., \& Dossetor, D. (2007). Intellectual ability, self-perceived social competence, and depressive symptomatology in children with high-functioning autistic spectrum disorders. J Autism Dev Disord, 37(9), 1647-1664. Retrieved from http://dx.doi.org/10.1007/s10803-006-0292-x. doi:10.1007/s10803-006-0292-x

Wallace, S., Fein, D., Rosanoff, M., Dawson, G., Hossain, S., Brennan, L., . . Shih, A. (2012). A global public health strategy for autism spectrum disorders. Autism Res, 5(3), 211-217. Retrieved from http://dx.doi.org/10.1002/aur.1236. doi:10.1002/aur.1236

Weisbrot, D. M., Gadow, K. D., DeVincent, C. J., \& Pomeroy, J. (2005). The presentation of anxiety in children with pervasive developmental disorders. J Child Adolesc Psychopharmacol, 15(3), 477 496. Retrieved from http://dx.doi.org/10.1089/cap.2005.15.477. doi:10.1089/cap.2005.15.477

Weitlauf, A. S., McPheeters, M. L., Peters, B., Sathe, N., Travis, R., Aiello, R., . . Warren, Z. (2014). Therapies for Children With Autism Spectrum Disorder: Behavioral Interventions Update. AHRQ Comparative Effectiveness Reviews. Retrieved from http://dx.doi.org/. 
West, L., Brunssen, S. H., \& Waldrop, J. (2009). Review of the evidence for treatment of children with autism with selective serotonin reuptake inhibitors. J Spec Pediatr Nurs, 14(3), 183-191. Retrieved from http://dx.doi.org/10.1111/j.1744-6155.2009.00196.x. doi:10.1111/j.17446155.2009.00196.x

West, L., Waldrop, J., \& Brunssen, S. (2009). Pharmacologic treatment for the core deficits and associated symptoms of autism in children. J Pediatr Health Care, 23(2), 75-89. Retrieved from http://dx.doi.org/10.1016/j.pedhc.2008.12.001. doi:10.1016/j.pedhc.2008.12.001

Whitehouse, A. J. O., Watt, H. J., Line, E. A., \& Bishop, D. V. M. (2009). Adult psychosocial outcomes of children with specific language impairment, pragmatic language impairment and autism. Int J Lang Commun Disord, 44(4), 511-528. Retrieved from http://dx.doi.org/10.1080/13682820802708098. doi:10.1080/13682820802708098

Williamson, S., Craig, J., \& Slinger, R. (2008). Exploring the relationship between measures of selfesteem and psychological adjustment among adolescents with Asperger syndrome. Autism, 12(4), 391-402. Retrieved from http://dx.doi.org/10.1177/1362361308091652. doi:10.1177/1362361308091652

584 Wink, L. K., Erickson, C. A., Stigler, K. A., \& McDougle, C. J. (2011). Riluzole in autistic disorder. J Child from http://dx.doi.org/10.1089/cap.2010.0154.doi:10.1089/cap.2010.0154 in children with pervasive developmental disorder revisited. J Am Acad Child Adolesc Psychiatry, 36(11), 1552-1559; discussion 1559-1560. Retrieved from http://dx.doi.org/10.1016/s0890-8567(09)66564-3. doi:10.1016/s0890-8567(09)66564-3 